\title{
Is It Necessary to Perform a Routine Antibiotic Prophylaxis before an Elective Surgery of Cesarean Section?
}

\author{
Sergei Belyaev ${ }^{1 *}(\mathbb{D})$, Larysa Nazarenko ${ }^{1}$, Liliya Dubrova ${ }^{1}$, Olena Fedota ${ }^{2}$ \\ ${ }^{1}$ Department of Genetics, Obstetrics, Gynecology and Fetal Medicine, Kharkiv Medical Academy of Postgraduate Education, \\ Kharkiv, Ukraine; ${ }^{2}$ Department of Obstetrics and Gynecology, V. N. Karazin Kharkiv National University, Kharkiv, Ukraine
}

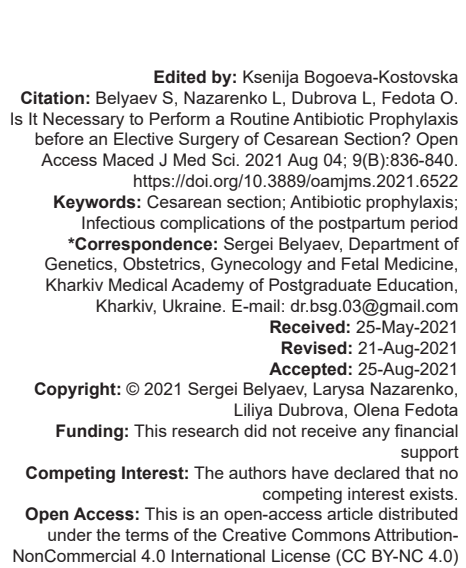

\section{Introduction}

Caesarean section is one of the most frequently performed delivery operations in modern obstetrics. According to statistics provided by the Department of Health Care of the Kharkiv City Council for 2019, the frequency of this operation varies from 16 to $40 \%$ of all births in various obstetric institutions in Kharkiv, and in recent years these numbers have a tendency to increase.

Despite the fact that caesarean section is among clean or conditionally clean surgical interventions, the risk of infectious complications in which is $2-10 \%$, the clinical protocols of many countries, including Ukraine, prescribe the mandatory antibiotic prophylaxis before or during the surgery with a difference only in the choice of specific antibacterial drugs or their combinations with local antiseptic agents [1], [2], [3], [4]. This is motivated by the fact that the preventive administration of antibiotics before the surgery can reduce the risk of endometritis by $60 \%$ and wound infection by $70 \%$ [5].

Nevertheless, despite the certain benefits of antibiotics in the prevention of postoperative complications, their use is associated with significant risks. In 2018, the World Health Organization (WHO) published antimicrobial resistance surveillance data demonstrating a high level of antibiotic resistance of a number of serious bacterial infections in both high- and low-income countries. According to the data by new WHO Global Antimicrobial Resistance Surveillance System (GLASS), about 500,000 people with suspected bacterial infection in 22 countries around the world 
have experienced antibacterial resistance [6]. Cases of infection resistance to antibiotics of not the penicillin series only, but also to fluoroquinolones, which are traditionally used as reserve drugs, the resistance of microflora to which develops much more slowly, have become significantly more frequent. Thus, the resistance of the microbial flora to penicillin, according to the same $\mathrm{WHO}$ report, reaches $51 \%$, and resistance to ciprofloxacin is 8-65\% [6].

The question of how harmless is the use of antibiotics before caesarean section surgery in connection with their passage through the placental barrier and a sufficiently rapid entry into the bloodstream of the fetus remains disputable. The results of studies devoted to the relationship between the prophylactic administration of cephalosporins to mothers and hyperbilirubinemia in newborns are few, contradictory, and need to be clarified [7], [8]

Based on the foregoing, we attempted to carry out elective caesarean section operations without antibiotic prophylaxis in somatically healthy women with a low risk of developing infectious complications in the obstetric department of the city clinical maternity hospital in an oblast center of eastern Ukraine (Kharkiv).

\section{Purpose of the study}

The purpose of the study was to justify the possibility of carrying out elective cesarean section operations without routine antibiotic prophylaxis.

\section{Study materials and methods}

From 2017 to 2019, 693 cesarean section operations were performed in the obstetric department, including 333 elective ones. Indications for the latter were a scar on the uterus, an anatomically narrow pelvis or abnormalities of the pelvic bones, incorrect presentation of the fetus, placenta previa, and other (combined) factors. The reasons for emergency surgical delivery were a functionally narrow pelvis (obstructive labor), anomalies of labor, acute or progressive fetal distress, placental abruption, and progression of the severity of late gestosis.

Patients for this study were selected from those having indications for elective caesarean section. The main group (Group-1) included 118 patients who were not prescribed with antibiotic prophylaxis. Inclusion criteria were as follows: Healthy women at the term of full-term pregnancy with no history of any chronic somatic or gynecological diseases, spontaneous or artificial abortions, hemorrhagic complications during previous pregnancies and deliveries, as well as the absence of similar complications during the present pregnancy.
Indications for the surgery were a scar on the uterus, an anatomically narrow pelvis and malpresentations of the fetus.

The control group (Group-2) consisted of the remaining 215 patients who underwent antibiotic prophylaxis by a single intravenous injection of $1 \mathrm{~g}$ of ceftriaxone intraoperatively after extraction of the fetus. We chose the intraoperative method of administering the antibiotic in order to maximize the safety of its passage through the placental barrier to the fetus, as well as taking into account the results of a randomized controlled trial that showed the same effectiveness in the prevention of infectious complications with administration of an antibiotic before or during surgery [8]. Isolated cases of continued antibiotic therapy in the post-operative period were dictated by the expansion of the scope of surgery or complications of the post-operative period.

Vagina preparation in all patients before the operation was performed using drug product containing a lyophilized culture of lactobacteria $L$. casei rhamnosus Doderlein, which are Gram-positive anaerobic non-sporeforming bacteria exhibiting antagonistic activity against a broad range of pathogenic and conditionally pathogenic bacteria (including Staphylococcus spp., Proteus spp., and enteropathogenic Escherichia coli), and at the same time not affecting the natural vaginal microbiocenosis [9].

Particular attention was paid to the quality of hand treatment by the medical personnel involved in the operation, as well as strict adherence to asepsis and antiseptic rules in the operating ward.

A comparative analysis of clinical groups was performed according to the following criteria:

- Vaginal microbiocenosis before surgical delivery;

- The duration and features of the operation;

- Clinical blood count on days 1 and 5 of the postoperative period;

- The condition of post-operative sutures, the presence of discharge from the wound, as well as signs of infectious complications from the uterus or other organs;

- The rate of uterine involution by ultrasonography;

- Duration of hospital stay before and after surgery;

- Prospective follow-up for 1 month after discharge from the maternity ward.

Statistical analysis of normally distributed data was carried out by parametric methods. Statistical hypotheses were tested using the t-test. The Fisher's angular transformation method was used to assess the reliability of the difference between the relative indicators. Conclusions regarding statistical hypotheses were made at a significance level of $p<0.05$. 
The design of research was approved by the Kharkiv Medical Academy of the post-diploma education. It was recognized to be in conformity with the principles of the Helsinki Declaration of the General Assembly of the World Medical Association (1964-2000), the European Council Convention on Human Rights and Biomedicine (1997), the International Council of Medical Scientific Communities and International Code of Medical Ethics and the rights of Ukraine.

\section{Results}

Microbiological examination of the vaginal discharge before the surgical delivery was performed in $86.4 \%$ of pregnant women of Group 1 and in $90.7 \%$ of Group 2 (Table 1). The vast majority of patients in both clinical groups $(78.4 \%$ of the main group and $74.9 \%$ of the control group) had normal vaginal microbiocenosis with predominance of lactobacteria. The rest showed mixed and conditionally pathogenic microflora, including lactobacteria, enterococci, epidermal staphylococci and fungi (Candida albicans), and, occasionally, pathological microflora represented by S. pyogenes, S. aureus, and S. agalactiae (Table 1).

Table 1: Data of infectological examination and duration of hospital stay before surgical delivery

\begin{tabular}{lll}
\hline Parameters & Group-1 & Group-2 \\
\hline Vaginal microbiocenosis, $\mathrm{n}(\%)$ & & \\
$\quad$ Predominance of lactobacteria & $80(78.4 \%)$ & $146(74.9 \%)$ \\
$\quad$ Mixed and conditionally pathogenic microflora & $12(11.8 \%)$ & $33(16.9 \%)$ \\
Pathological microflora & $10(8.5 \%)$ & $36(16.7 \%)$ \\
S. pyogenes, & $2(2.0 \%)$ & $8(3.7 \%)$ \\
S. aureus, & $4(3.9 \%)$ & $16(7.4 \%)$ \\
S. agalactiae & $4(3.9 \%)$ & $12(5.6 \%)$ \\
Duration of hospital stay before the surgery, & $4.24 \pm 0.19$ & $4.50 \pm 0.30$ \\
days $(\mathrm{X} \pm \mathrm{Sx})$ & \\
\hline The difference between the rates in the comparison groups is statistically incorrect. &
\end{tabular}

The duration of stay of pregnant women before elective surgical delivery in our hospital turned out to be approximately the same in both clinical groups and amounted to about 4 days (Table 1). Often, early hospitalization was associated with the need for additional consultations or examinations. Nevertheless, the duration of stay of patients in the ward before the surgery directly correlates with the risk of infectious complications in the postoperative period, and therefore, admission to the hospital on the eve of the operation should be considered optimal [10].

The duration of cesarean section in both clinical groups, as a rule, did not exceed $1 \mathrm{~h}$ and was performed in a standard scope (Table 2). Cases of prolonged intervention time were associated with the need for additional hemostasis, the expansion of the scope of the operation, or the technical difficulties of its implementation (adhesive process). The volume of intraoperative blood loss, at the same time, did not exceed $500 \mathrm{ml}$ in $82-88 \%$ of the cases. We have not observed a single case of pathological blood loss of
Table 2: Surgical intervention features

\begin{tabular}{lll}
\hline Parameters & Group-1 & Group-2 \\
\hline Duration of surgery, $\mathrm{n}(\%)$ & & \\
Up to $40 \mathrm{~min}$ & $45(38.1 \%)$ & $77(35.8 \%)$ \\
$40-60 \mathrm{~min}$ & $58(49.2 \%)$ & $105(48.8 \%)$ \\
More than 1 $\mathrm{h}$ & $15(12.7 \%)$ & $33(15.3 \%)$ \\
Expansion of scope and complication of the surgery, $\mathrm{n}(\%)$ & & \\
$\quad$ Sterilization & $11(9.3 \%)$ & $12(5.6 \%)$ \\
Adhesive process & $4(3.4 \%)$ & $9(4.2 \%)$ \\
Ligation of the uterine vessels & $6(5.1 \%)$ & $4(1.9 \%)$ \\
Conservative myomectomy & $6(5.1 \%)$ & $12(5.6 \%)$ \\
Cystectomy & $7(5.9 \%)$ & $4(1.9 \%)$ \\
Supravaginal amputation of the uterus & - & $2(0.9 \%)$ \\
Blood loss during the surgery, $\mathrm{n}(\%)$ & & \\
Up to 500 ml & $97(82.2 \%)$ & $190(88.4 \%)$ \\
500-1000 ml & $21(17.8 \%)$ & $25(11.6 \%)$ \\
More than 1 L & - & - \\
\hline The difference between the rates in the comparison groups is statistically incorrect. &
\end{tabular}

more than $1 \mathrm{I}$ among the electively operated patients (Table 2).

The early post-operative period was unremarkable in $94 \%$ of patients of both clinical groups; however, all women were under our follow-up for 1 month after the surgery, which provided the possibility of identifying late complications of the postpartum period. Peripheral blood parameters (the absolute number of leukocytes, and leukocyte formula), the process of involution of the uterus and the associated clinical symptoms of infectious complications, the state of the postoperative suture, and the time spent in the hospital after childbirth were analyzed (Table 3).

Table 3: Post-operative period characteristics

\begin{tabular}{|c|c|c|}
\hline Parameters & Group-1 & Group-2 \\
\hline \multicolumn{3}{|c|}{$\begin{array}{l}\text { Duration of stay in inpatient department after the surgery, } \\
\text { days }\end{array}$} \\
\hline$(X \pm S x)$ & $4.99 \pm 0.12$ & $4.76 \pm 0.05$ \\
\hline More than 5 days, $\mathrm{n}(\%)$ & $17(14.4 \%)$ & $25(11.7 \%)$ \\
\hline \multicolumn{3}{|c|}{$\begin{array}{l}\text { Peripheral blood leukocytes on the first day after the } \\
\text { surgery, } n(\%)\end{array}$} \\
\hline Up to $9 \times 10^{9} / \mathrm{L}$ & $14(11.9 \%)$ & $42(19.5 \%)$ \\
\hline $9-15 \times 10^{9} / \mathrm{L}$ & $70(59.3 \%)$ & $144(67.0 \%)$ \\
\hline $15-20 \times 10^{9} / \mathrm{L}$ & $25(21.2 \%)^{*}$ & $24(11.2 \%)$ \\
\hline More than $20 \times 10^{9} / \mathrm{L}$ & $8(6.8 \%)^{*}$ & $4(1.9 \%)$ \\
\hline \multicolumn{3}{|c|}{$\begin{array}{l}\text { Proportion of blood segmented neutrophils on the } 1^{\text {st }} \text { day } \\
\text { after the surgery, } n(\%)\end{array}$} \\
\hline Up to $6 \%$ & $85(72.0 \%)$ & $142(66.0 \%)$ \\
\hline More than $6 \%$ & $33(28.0 \%)$ & $73(34.0 \%)$ \\
\hline \multicolumn{3}{|c|}{$\begin{array}{l}\text { Peripheral blood leukocytes on the fifth day after the } \\
\text { surgery, } n(\%)\end{array}$} \\
\hline Up to $9 \times 10^{9} / \mathrm{L}$ & $67(56.8 \%)^{\star \star}$ & $164(76.3 \%)$ \\
\hline $9-15 \times 10^{9} / \mathrm{L}$ & $50(42.4 \%)^{\star *}$ & $46(21.4 \%)$ \\
\hline $15-20 \times 10^{9} / \mathrm{L}$ & - & $4(1.9 \%)$ \\
\hline More than $20 \times 10^{9} / \mathrm{L}$ & - & - \\
\hline \multicolumn{3}{|c|}{$\begin{array}{l}\text { Proportion of blood segmented neutrophils on the fifth day } \\
\text { after the surgery, } \mathrm{n}(\%)\end{array}$} \\
\hline Up to $6 \%$ & $105(89.0 \%)$ & $183(85.1 \%)$ \\
\hline More than $6 \%$ & $13(11.0 \%)$ & $32(14.9 \%)$ \\
\hline \multicolumn{3}{|c|}{ Complications of post-operative period, $\mathrm{n}(\%)$} \\
\hline Gapping of the post-operative suture & $1(0.9 \%)$ & $3(1.4)$ \\
\hline Subinvolution of the uterus & $4(3.4 \%)$ & $7(3.3 \%)$ \\
\hline Lochiometra & $2(1.7 \%)$ & $3(1.4 \%)$ \\
\hline
\end{tabular}

In the group of patients operated without prescription of antibiotics, there were significantly more cases compared to the control, when the number of peripheral blood leukocytes on the $1^{\text {st }}$ day after the operation exceeded $15 \times 10^{9} /$ (Table 3 ). In the future, by the $15^{\text {th }}$ day, there was a rapid decrease in the level of leukocytosis, although its level in the range of $9-15 \times 10^{9} / /$ significantly more often exceeded that in the control group. The leukogram, however, 
did not undergo any changes characteristic of the inflammatory process, which allows us to interpret the described features as an adaptive reaction, more pronounced in the absence of the immunosuppressive effect of antibiotics.

The process of uterine involution after delivery was monitored in all women using ultrasound scanning. In addition to the absolute dimensions, the width of the uterine cavity and the presence of contents in it were taken into account, and the information obtained was compared with the clinical features of a particular case [11], [12].

The post-operative period complications included post-operative wound dehiscence and the lochiometra, which was an indication for prolonging antibiotic therapy. Cases of uterine subinvolution, not complicated by endometritis, were managed conservatively without antibiotics (Table 3). The statistical analysis performed did not reveal any significant differences between the number of infectious complications in the comparison groups, which allows us to conclude that there is no relationship between routine antibiotic prophylaxis before cesarean section and the risk of infectious complications in the postoperative period.

Scheduled discharge from the hospital of patients after cesarean section, in the case of a smooth course of the post-operative period, occurred on the $5^{\text {th }}$ day after the operation. The reasons for the delay of a woman in the hospital were complications of the postpartum period or the condition of the newborn, requiring treatment and medical support. The number of such cases did not significantly differ between groups and amounted to no more than $14 \%$ of the total number of electively operated women (Table 3 ).

\section{Discussion}

Solving the problem of the postoperative infectious complications using the antibiotics and antiseptics has been the subject of close attention of researchers for the last years. The subject of discussion is the ways to use the antibacterial drugs (parenterally or locally), the time of their administration (before the surgery, intraoperatively or within the postsurgery period), as well as the choice of a specific drug and its dosage [13], [14], [15]. The last thing is considered to be especially important due to the proven fact of the spread of resistant microflora. It leads to the need for frequent changes in antibiotics used in a particular medical institution. It is connected with a wide range of medicines used for routine prevention of the infectious complications: Azithromycin, clavulanic acid, metronidazole, cefazolin, gentamicin, and clindamycin [13], [16], [17]. However, the progressive decrease in the effectiveness of antibacterial agents leads to the search for alternative methods, devoid of these disadvantages [18].

The studies during the last years suggest that the absence of the post-surgery infectious complications during the planned surgeries is far from always associated with the routine use of antibacterial drugs, but depends on the big number of accompanying factors, among which there are the organization of the work of medical personnel, the strict complying with the rules of aseptics and antiseptics in the operating unit and the proper preparation of the patient, including the conduct of hygiene procedures [2]. It makes possible to substantially decrease the dose of antibiotics used for prophylactic purposes, or completely abandon them, using locally acting, vaginal forms of medicines, without worsening postoperative outcomes at all [15], [19]. It is consistent with the results of our research, on the ground of which we propose an individual approach to the prevention of infectious complications during elective cesarean section operations. Managing the women with a low risk of infection realization, it is advisable to abandon the routine use of antibiotics, preferring the vaginal use of a lyophilized culture of lactobacilli $L$. casei rhamnosus Doderlein. An absolute requirement, in this case, remains the rational organization of the work of the operating unit personnel with the strict complying with the rules of aseptics and antiseptics.

\section{Conclusions}

No relationship has been identified between the routine prescription of antibiotics before or during an elective caesarean section and the risk of developing infectious complications in the postoperative period.

Antibiotic prophylaxis before surgery should be carried out differentially, taking into account the history and features of the course of this pregnancy. Prophylactic administration of antibiotics to healthy women, without concomitant infectious pathology, with a smooth course of the gestational process is inappropriate.

\section{References}

1. Klinichnyi Protokol z Akusherskoi Dopomohy Kesariv Roztyn: Nakaz MOZ Ukrainy Vid 27.12.2011 No. 977, Kyiv; 2011. Available from: https://www.zakon.rada.gov.ua/rada/card/ v0977282-11. [Last accessed on 2020 Feb 14].

2. Dieplinger B, Egger M, Jezek C, Heinisch-Finke C, Altendorfer C Pernerstorfe $\mathrm{T}$, et al. Implementation of a comprehensive unitbased safety program to reduce surgical site infections in cesarean delivery. Am J Infect Control. 2020;48(4):386-90. https://doi.org/10.1016/j.ajic.2020.01.016

PMid:32093979

3. Ben Shoham A, Bar-Meir M, loscovich A, Samueloff A, 
Wiener-Well Y. Timing of antibiotic prophylaxis in cesarean section: Retrospective, difference-in-differences estimation of the effect on surgical-site-infection. J Matern Fetal Neonatal Med. 2019;32(5):804-8. https://doi.org/10.1080/14767058.2017.1391784 PMid:29020828

4. Wilson RD, Caughey AB, Wood SL, Macones GA, Wrench IJ, Huang $\mathrm{J}$, et al. Guidelines for antenatal and preoperative care in cesarean delivery: Enhanced recovery after surgery society recommendations (Part 1). Am J Obstet Gynecol. 2018;219(6):523.e1-5. https://doi.org/10.1016/j. ajog.2018.09.015

PMid:30240657

5. Smaill FM, Gyte GM. Antibiotic prophylaxis versus no prophylaxis for preventing infection after cesarean section. Cochrane Database Syst Rev. 2014;10:CD007482. https://doi. org/10.1002/14651858.cd007482.pub2 PMid:25350672

6. A new $\mathrm{WHO}$ report on antibiotic resistance. Based on the materials of the Ukrainian medical periodical. 2018;2. Available from: https://www.umj.com.ua/article/120095/novyj-doklad-vozpo-antibiotikorezistentnosti. [Last accessed on 2019 Dec 24].

7. Hayasaki M, Hanabayashi T, Ri J, Takada Y, Ito K, Noda K, et al. Pharmacokinetic and clinical studies of cefotiam in the perinatal period. Jpn J Antibiot. 1986;39(9):2497-518.

PMid:3467093

8. Osman B, Abbas A, Ahmed MA, Abubaker MS, Adam I. Prophylactic ceftizoxime for elective cesarean delivery at Soba Hospital, Sudan. BMC Res Notes. 2013;6:57. https://doi. org/10.1186/1756-0500-6-57

PMid:23394621

9. Tapilskaya NI, Savicheva AM, Shipitsyina EV. Lactoginal for correction of abnormal vaginal microbiocenosis in pregnant woman with cervical cerclage: Clinical case and literature review. Zhurnal Akusherstva Zhenskih Bolnezney. 2016;65(6):89-95. Available from: https://cyberleninka.ru/ article/n/primenenie-preparata-laktozhinal-dlya-korrektsiinarusheniya-mikrobiotsenoza-vlagalischa-u-beremennoys-nalozhennym-shvom-na-sheyku/viewer. https://doi. org/10.17816/jowd65689-95

10. Shao J, Zhang H, Yin B, Li J, Zhu Y, Zhang Y. Risk factors for surgical site infection following operative treatment of ankle fractures: A systematic review and meta-analysis. Int J Surg. 2018;56:124-32. https://doi.org/10.1016/j.ijsu.2018.06.018 PMid:29929022

11. Ryiskeldieva VT. Uterus subinvolution as risk factors in the postnatal endometritis. Tavricheskiy Med Biologicheskiy Vestnik. 2012;15(1):212-5. Available from: http://www.dspace. nbuv.gov.ua/handle/123456789/44991.

12. Mulic-Lutvica A, Bekuretsion M, Bakos $\mathrm{O}$, Axelsson O. Ultrasonic evaluation of the uterus and uterine cavity after normal, vaginal delivery. Ultrasound Obstet Gynecol. 2001;18(5):491-8. https:// doi.org/10.1046/j.0960-7692.2001.00561.x

PMid: 11844171

13. Suliman SM, Yousef BA, Hamadelnil AA. Impact of guidelines implementation for the rational use of prophylactic antibiotics in elective cesarean sections at elqutainah teaching hospital. J Family Med Prim Care. 2020;9(1):162-7. https://doi. org/10.4103/jfmpc.jfmpc_903_19 PMid:32110584

14. Sway A, Wanyoro A, Nthumba P, Aiken A, Ching P, Maruta A, et al. Prospective cohort study on timing of antimicrobial prophylaxis for post-cesarean surgical site infections. Surg Infect (Larchmt). 2020;21(6):552-7. https://doi.org/10.1089/ sur.2018.226

PMid:31951506

15. La Rosa M, Omere C, Redfern T, Abdelwahab M, Spencer N Villarreal $\mathrm{J}$, et al. The impact of low-dose versus high-dose antibiotic prophylaxis regimens on surgical site infection rates after cesarean delivery. Arch Gynecol Obstet. 2020;301(1):69-73. https://doi.org/10.1007/s00404-019-05370-y PMid:31811413

16. Kawakita T, Huang CC, Landy HJ. Choice of prophylactic antibiotics and surgical site infections after cesarean delivery. Obstet Gynecol. 2018;132(4):948-55. https://doi.org/10.1097/ aog.0000000000002863 PMid:30204697

17. Watson D, Tita A, Dimperio L, Howard T, Harper L. Antibiotic prophylaxis for cesarean delivery among Alabama providers. South Med J. 2019;112(3):170-3. https://doi.org/10.14423/ smj.0000000000000943 PMid:30830231

18. Gandra S, TrettA, Alvarez-Uria G, Solomkin JS, Laxminarayan R. Is the efficacy of antibiotic prophylaxis for surgical procedures decreasing? Systematic review and meta-analysis of randomized control trials. Infect Control Hosp Epidemiol. 2019;40(2):133-41. https://doi.org/10.1017/ice.2018.295 PMid:30417800

19. Haas DM, Morgan S, Contreras K, Kimball S. Vaginal preparation with antiseptic solution before cesarean section for preventing postoperative infections. Cochrane Database Syst Rev. 2020;4(4):CD007892. https://doi.org/10.1002/14651858. cd007892.pub7

PMid:32335895 